Proceedings of the International Conference on Oxide Materials for Electronic Engineering, May 29-June 2, 2017, Lviv

\title{
Physical Properties of the $\left(\mathrm{Ga}_{70} \mathrm{La}_{30}\right)_{2} \mathrm{~S}_{300}$, $\left(\mathrm{Ga}_{69.75} \mathrm{La}_{29.75} \mathrm{Er}_{0.5}\right)_{2} \mathrm{~S}_{300}$ Single Crystals
}

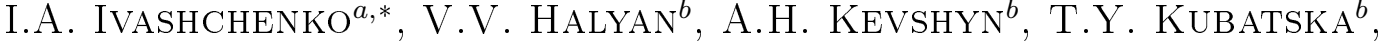 \\ V.M. ROSOlOVSKA ${ }^{b}$, P.V. TISHChENKO ${ }^{a}$ AND I.D. OLEKSEYUK ${ }^{a}$
}

${ }^{a}$ Department of Inorganic and Physical Chemistry, Eastern European National University, 43025, Lutsk, Ukraine

${ }^{b}$ Department of Experimental Physics, Eastern European National University, 43025, Lutsk, Ukraine

Using solution-melt method two single crystals, $\left(\mathrm{Ga}_{70} \mathrm{La}_{30}\right)_{2} \mathrm{~S}_{300},\left(\mathrm{Ga}_{69.75} \mathrm{La}_{29.75} \mathrm{Er}_{0.5}\right)_{2} \mathrm{~S}_{300}$, were grown. The maxima of the luminescent radiation in the photoluminescence spectrum of the $\left(\mathrm{Ga}_{69.75} \mathrm{La}_{29.75} \mathrm{Er}_{0.5}\right)_{2} \mathrm{~S}_{300} \operatorname{single}_{3}$ crystal correspond to the intracentric transitions in the erbium ions: ${ }^{2} H_{11 / 2} \rightarrow{ }^{4} I_{15 / 2}(525 \mathrm{~nm})$ and ${ }^{4} S_{3 / 2} \rightarrow{ }^{4} I_{15 / 2}$ (545 nm).

DOI: $10.12693 /$ APhysPolA.133.994

PACS/topics: 61.82.Fk, 71.20.Eh, 78.20.-e, 78.55.-m

\section{Introduction}

The current research in the field of solid state chemistry follows the scheme:

composition $\rightarrow$ structure $\rightarrow$ properties $\rightarrow$ composition,

as modern technical progress requires the constant search for new materials that satisfy the demands of modern technology. Scientists are paying special attention to the properties of crystalline and amorphous media that are able to consistently show high-intensity conversion and up-conversion photoluminescence (PL) and non-linear optical (NLO) properties $[1,2]$. That is why we are interested in the $\mathrm{Ga}_{2} \mathrm{~S}_{3}-\mathrm{La}_{2} \mathrm{~S}_{3}$ system, because ternary semiconductors are formed in it and there is also a region of glass forming there [3]. Previous investigations of the $\mathrm{Ga}_{2} \mathrm{~S}_{3}-\mathrm{La}_{2} \mathrm{~S}_{3}$ system found two ternary compounds, $\mathrm{GaLaS}_{3}$ and $\mathrm{Ga}_{1.67} \mathrm{La}_{3} \mathrm{~S}_{7} \cdot \mathrm{GaLaS}_{3}$ forms in a peritectic reaction $\mathrm{L}+\mathrm{Ga}_{1.67} \mathrm{La}_{3} \mathrm{~S}_{7} \leftrightarrow \mathrm{GaLaS}_{3}$ at $1223 \mathrm{~K}$, crystallizes in the monoclinic structure, S.G. $P 2_{1} / c$, $a=1.517(8) \mathrm{nm}, b=1.056(4) \mathrm{nm}, c=1.282(6) \mathrm{nm}$, $\beta=137.70\left(\alpha-\mathrm{GaLaS}_{3}\right)[3]$ or in the orthorhombic structure, S.G. Pna $2_{1}, a=1.0405(1) \mathrm{nm}, b=2.1984(2) \mathrm{nm}$, $c=0.60565(5) \mathrm{nm}\left(\beta-\mathrm{GaLaS}_{3}\right)$ [4]. Electronic structure calculations of $\mathrm{GaLaS}_{3}$ indicate that $\beta$-type is an indirect and $\alpha$-type is a direct band gap semiconductor. The weak NLO response of $\beta$-GaLaS 3 has been detected [4]. The insertion of dopants like rare earth metals $\mathrm{Pr}^{3+}, \mathrm{Nd}^{3+}$, $\mathrm{Dy}^{3+}, \mathrm{Er}^{3+}[1,5-9]$ to binary or ternary compounds, is a condition for the production of media for laser technology and telecommunications.

\section{Material and equipment}

The single crystals of the $\left(\mathrm{Ga}_{70} \mathrm{La}_{30}\right)_{2} \mathrm{~S}_{300}$, $\left(\mathrm{Ga}_{69.75} \mathrm{La}_{29.75} \mathrm{Er}_{0.5}\right)_{2} \mathrm{~S}_{300}$ compositions were grown

\footnotetext{
* corresponding author; e-mail:

Ivashchenko. inna@eenu . edu .ua
}

by solution-melt method from the primary crystallization range of the $\mathrm{GaLaS}_{3}$. The compositions and the growth conditions were selected using the $\mathrm{Ga}_{2} \mathrm{~S}_{3}-\mathrm{La}_{2} \mathrm{~S}_{3}$ phase diagram [3]. The supercooling of the solid solution was $70 \mathrm{~K}$ as determined from the cooling thermograms of the samples. The synthesis of the starting alloy at maximum temperature $1200 \mathrm{~K}$ and the crystal growth was performed in the same evacuated quartz container with a conical bottom. The growth process was performed in a vertical two-zone furnace. The temperature gradient at the solid-melt interface was $20 \mathrm{~K} / \mathrm{cm}$. After melting the batch, the ampoule was lowered at a rate of $5 \mathrm{~mm} /$ day. Immediately after the crystallization of $10 \mathrm{~mm}$ along the ampoule, we followed by remelting $6.0-8.0 \mathrm{~mm}$ of the crystallized portion. Then the ampoule was annealed for $100 \mathrm{~h}$. After that, the crystal growth was performed at a rate of lowering of $5 \mathrm{~mm} /$ day. At the end of the process, both furnaces were cooled to $820 \mathrm{~K}$ at a rate of 50-70 K/day, and then cooled to room temperature with the furnaces switched off. The grey-yellow single crystals (in case of the $\left(\mathrm{Ga}_{70} \mathrm{La}_{30}\right)_{2} \mathrm{~S}_{300}$ colour was grey-pink) with a diameter of $10-13 \mathrm{~mm}$ and a length of $23-25 \mathrm{~mm}$ were obtained (Fig. 1). The photoluminescence spectra were investigated using an MDR-206 monochromator
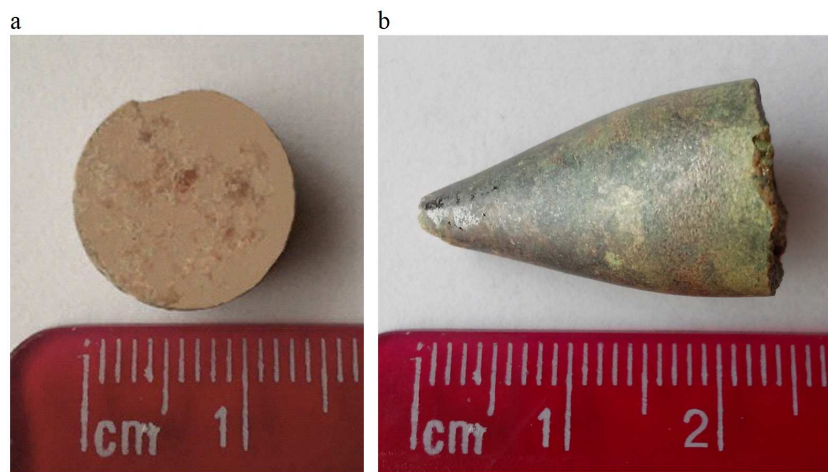

Fig. 1. Obtained (Ga70La30) ${ }_{2} \mathrm{~S}_{300}$ (a), $\left(\mathrm{Ga}_{69.75} \mathrm{La}_{29.75} \mathrm{Er}_{0.5}\right)_{2} \mathrm{~S}_{300}$ (b) single crystals. 
at room temperature. The signal was registered by $\mathrm{Si}$ and $\mathrm{PbS}$ photosensors. The luminescence excitation was performed by a $400 \mathrm{~mW}$ laser at $810 \mathrm{~nm}$ wavelength.

\section{Results and discussion}

The single crystals $\left(\mathrm{Ga}_{70} \mathrm{La}_{30}\right)_{2} \mathrm{~S}_{300}$, $\left(\mathrm{Ga}_{69.75} \mathrm{La}_{29.75} \mathrm{Er}_{0.5}\right)_{2} \mathrm{~S}_{300}$ were indexed in the orthorhombic structure, S.G. Pna $2_{1}, a=1.0412(2) \mathrm{nm}$, $b=2.1966(4) \mathrm{nm}, \quad c=0.6052(3) \mathrm{nm}$ for $\left(\mathrm{Ga}_{70} \mathrm{La}_{30}\right)_{2} \mathrm{~S}_{300}$ with good agreement with [4] and $a=1.0419(1) \mathrm{nm}, b=2.1975(2) \mathrm{nm}, c=0.6057(3) \mathrm{nm}$ for $\left(\mathrm{Ga}_{69.75} \mathrm{La}_{29.75} \operatorname{Er}_{0.5}\right)_{2} \mathrm{~S}_{300}$ (Fig. 2).

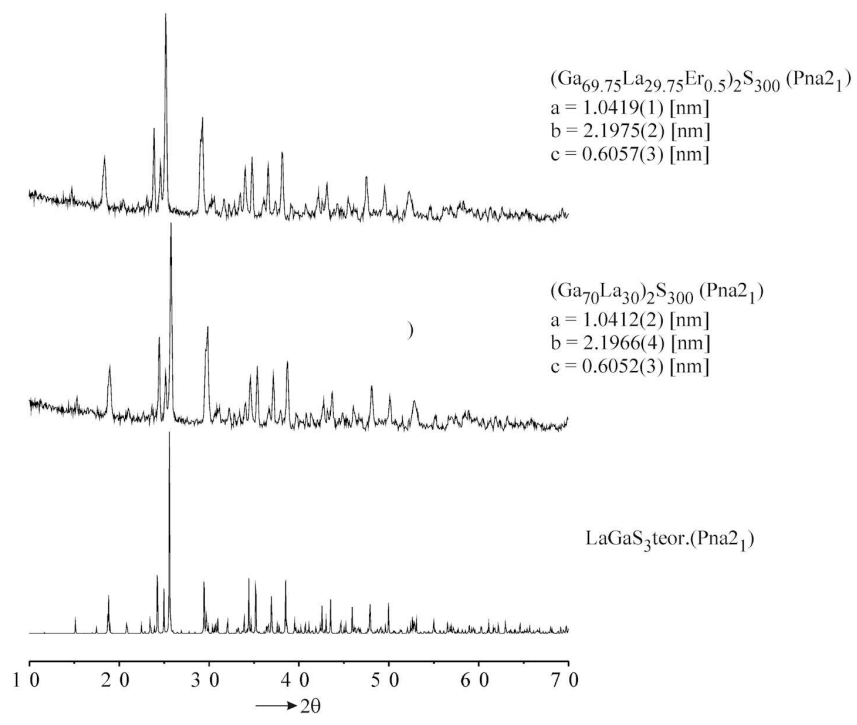

Fig. 2. Diffraction patterns of the obtained single crystals.

Up-conversion $\mathrm{PL}$ spectrum in the spectral range $510-560 \mathrm{~nm}$ (Fig. 3) consists of two peaks at 525 and $545 \mathrm{~nm}$, with the ratio of the intensity at their maxima being $I_{545 / 525}=4.2$. Characteristic narrow maxima and PL absence in the $\left(\mathrm{Ga}_{70} \mathrm{La}_{30}\right)_{2} \mathrm{~S}_{300}$ crystal means that the emission in the $\left(\mathrm{Ga}_{69.75} \mathrm{La}_{29.75} \mathrm{Er}_{0.5}\right)_{2} \mathrm{~S}_{300}$ single crystal is caused by the intra-center transitions in $\mathrm{Er}^{3+}$ ions, namely ${ }^{2} H_{11 / 2} \rightarrow{ }^{4} I_{15 / 2}$ and ${ }^{4} S_{3 / 2} \rightarrow{ }^{4} I_{15 / 2}$ for 525 and $545 \mathrm{~nm}$, respectively. The absorption of IR quanta $(810 \mathrm{~nm})$ yields green luminescence, with higher energy quanta. Such a phenomenon (so called up-conversion photoluminescence) is especially common in erbium-doped chalcogenide glasses [10]. This can occur by sequential absorption of two photons with $810 \mathrm{~nm}$ wavelength; or when one erbium ion is in excited ${ }^{4} I_{9 / 2}$ state, energy is transferred to another ${ }^{4} I_{9 / 2}$-excited ion nearby

$$
\begin{aligned}
& { }^{4} I_{15 / 2}+h \nu_{810} \rightarrow{ }^{4} I_{9 / 2}+h \nu_{810} \rightarrow{ }^{2} H_{9 / 2}, \\
& { }^{4} I_{9 / 2}+{ }^{4} I_{9 / 2} \rightarrow{ }^{4} I_{15 / 2}+{ }^{2} H_{9 / 2} .
\end{aligned}
$$

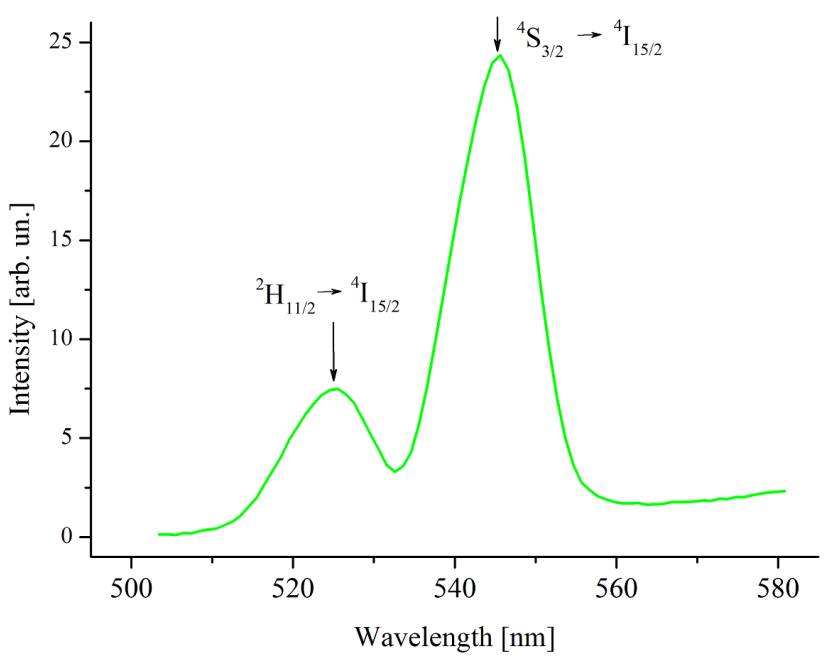

Fig. 3. Photoluminescence spectrum of the $\left(\mathrm{Ga}_{69.75} \mathrm{La}_{29.75} \mathrm{Er}_{0.5}\right)_{2} \mathrm{~S}_{300}$ single crystal at $300 \mathrm{~K}$.

The next step is non-radiative relaxation of erbium ions to the lower energy states or cross-relaxation involving ${ }^{2} H_{11 / 2}$ and ${ }^{4} S_{3 / 2}$ states. Thus, a high concentration of erbium ions in the ${ }^{2} H_{11 / 2}$ to ${ }^{4} S_{3 / 2}$ states is obtained through which $\mathrm{PL}$ radiation is emitted. This type of radiation is particularly promising for the manufacture of up-converters from infrared to visible light.

\section{Conclusions}

The single crystals of the $\left(\mathrm{Ga}_{70} \mathrm{La}_{30}\right)_{2} \mathrm{~S}_{300}$, $\left(\mathrm{Ga}_{69.75} \mathrm{La}_{29.75} \operatorname{Er}_{0.5}\right)_{2} \mathrm{~S}_{300}$ compositions were grown by solution-melt method from the primary crystallization range of the $\mathrm{GaLaS}_{3}$. Both samples were indexed in the orthorhombic structure, S.G. Pna $2_{1}, a=1.0412(2) \mathrm{nm}$, $b=2.1966(4) \mathrm{nm}, c=0.6052(3) \mathrm{nm}$ for $\left(\mathrm{Ga}_{70} \mathrm{La}_{30}\right)_{2} \mathrm{~S}_{300}$ and $a=1.0419(1) \mathrm{nm}, \quad b=2.1975(2) \mathrm{nm}$, $c=0.6057(3) \mathrm{nm}$ for $\left(\mathrm{Ga}_{69.75} \mathrm{La}_{29.75} \mathrm{Er}_{0.5}\right)_{2} \mathrm{~S}_{300}$. In the spectral range $510-560 \mathrm{~nm}$ the luminescence excitation was performed by a $400 \mathrm{~mW}$ laser at $810 \mathrm{~nm}$ wavelength led to photoluminescence in the $\left(\mathrm{Ga}_{69.75} \mathrm{La}_{29.75} \mathrm{Er}_{0.5}\right)_{2} \mathrm{~S}_{300}$ single crystal. The maxima of the luminescent radiation $(525 ; 545 \mathrm{~nm})$ correspond to the intracentric transitions ${ }^{2} H_{11 / 2} \rightarrow{ }^{4} I_{15 / 2}$ and ${ }^{4} S_{3 / 2} \rightarrow{ }^{4} I_{15 / 2}$ in the erbium ions, respectively.

\section{Acknowledgments}

This work was partially supported by the Project of Ministry of Education and Science of Ukraine (No. 0115U002348). 


\section{References}

[1] M. Frumar, B. Frumarova, T. Wagner, G.K. Sujan, Ref. Module Mater. Sci. Mater. Eng. 4, 206 (2011).

[2] M. Guittard, S. Jaulmes, A.M. Loireau-Lozac'h, A. Mazurier, F. Berguer, J. Flahaut, J. Solid State Chem. 58, 276 (1985).

[3] M. Julien-Pouzol, S. Jaulmes, C. Dagron, Acta Crystallogr. B 38, 1566 (1982).

[4] L. Peng, L. Longhua, Ch. Ling, W. Liming, J. Solid State Chem. 183, 444 (2010).

[5] M. Piasecki, M.G. Brik, I.E. Barchiy, K. Ozga, I.V. Kityk, A.M. El-Naggar, A.A. Albassam, T.A. Malakhovskaya, G. Lakshminarayana, J. Alloys Comp. 710, 600 (2017).

[6] A.H. Kevshyn, V.V. Halyan, H.Ye. Davydyuk, O.V. Parasyuk, I.I. Mazurets, Glass Phys. Chem. 36, $27(2010)$
[7] M. Piasecki, G.L. Myronchuk, O.V. Zamurueva O.Y. Khyzhun, O.V. Parasyuk, A.O. Fedorchuk, A. Albassam, A.M. El-Naggar, I.V. Kityk, Mater. Res. Expr. 3, 025902 (2016).

[8] I.A. Ivashchenko, I.V. Danyliuk, I.D. Olekseyuk, V.V. Halyan, J. Solid State Chem. 210, 102 (2014).

[9] V.V. Halyan, V.V. Strelchuk, V.O. Yukhymchuk, A.H. Kevshyn, G.Ye. Davydyuk, M.V. Shevchuk, S.V. Voronyuk, Physica B 411, 35 (2013).

[10] V.V. Halyan, I.V. Kityk, A.H. Kevshyn, I.A. Ivashchenko, G. Lakshminarayana, M.V. Shevchuk, A. Fedorchuk, M. Piasecki, J. Lumin. $\mathbf{1 8 1}, 315$ (2017) 